\title{
Directional Distance Functions and Rate-of-Return Regulation
}

\author{
Juan Aparicio and Jesus T. Pastor \\ Center of Operations Research (CIO), University Miguel Hernandez of Elche, Alicante, 03202 Elche, Spain
}

Correspondence should be addressed to Juan Aparicio, j.aparicio@umh.es

Received 7 April 2012; Accepted 14 May 2012

Academic Editor: Henry Schellhorn

Copyright (C) 2012 J. Aparicio and J. T. Pastor. This is an open access article distributed under the Creative Commons Attribution License, which permits unrestricted use, distribution, and reproduction in any medium, provided the original work is properly cited.

This paper is concerned with formulating directional distance functions assuming that firms operate subject to rate-of-return regulation. To this end, we consider two different contexts. First, we assume that input prices are known, which allows us to extend the rate of return regulated version of Farrell efficiency. Secondly, we assume that input prices are unknown, showing then that a specific reference direction arises as a natural choice for measuring efficiency with directional distance functions.

\section{Introduction}

All over the world, most countries deal with the problem of monopoly by means of regulation. This type of solution is widespread in the case of natural monopolies: water, natural gas, and electric companies. These companies are not allowed to charge any price they want to. Instead, government agencies regulate their output prices.

One form of regulation is that of rate-of-return regulation. After the firm subtracts its operating expenses from gross revenues, the remaining net revenue should be just sufficient to compensate the firm for its investment in plant and equipment. In particular, the regulator authorizes the output price which, if anticipated future market conditions are realized, results in the firm earning a rate of return equal to the predetermined allowed level upon which the output price has been estimated. At a subsequent stage, if the obtained firm rate of return is less than the allowed level, the firm can request an increase in the output price.

It is well known that one disadvantage of rate-of-return regulation is that it may encourage inefficiency because the regulated firms have no incentive to decrease costs. For this reason, assessing the performance of regulated companies with respect to technical inefficiency is an important issue for government agencies.

Measuring inefficiency of firms subject to rate-of-return regulation has been yet studied previously in the literature (see [1-4]). In particular, Färe and Logan [4] introduced and 
explored a regulated version of Farrell efficiency. Nevertheless, there are other alternatives to measure technical inefficiency in production theory. As Portela et al. [5] argue, on some markets it is not possible or is not desired to modify equiproportionately inputs or outputs. A well-known drawback of Farrell efficiency is the arbitrariness in imposing targets on the efficient frontier preserving the mix within inputs or within outputs, when really the firm's very reason to change its input and output levels is often the desire to change the mix (see [6]). If so, an efficiency measure that takes into account different changes in inputs or outputs could be more appropriate. In this sense, researchers could resort to use directional distance functions $[7,8]$. However, as far as we are aware no paper has been concerned with developing directional distance functions to measure efficiency for firms subject to rate-ofreturn regulation. Consequently, this paper is concerned with developing directional distance functions assuming this type of regulation. To this end, we consider two different contexts. First, we assume that input prices are known, which allows us to extend the rate-of-return regulated version of Farrell efficiency. Secondly, we assume that input prices are unknown, showing then that a specific reference direction arises as a natural choice for measuring efficiency with directional distance functions.

We have an additional justification for introducing in the literature directional distance functions under rate-of-return regulation. Granderson [9] used the Tornqvist index to measure productivity change for firms subject to rate-of-return regulation, given the production of a bad output. Nevertheless, this author claimed that he used the Tornqvist index instead of other possibilities because "use of the Malmquist-Luenberger index would require the development of such an index for firms subject to rate regulation" [9, page 273]. The MalmquistLuenberger index, which appeared in Chung et al. [10], makes use of directional distance functions in its expression. Therefore, in order to develop a Malmquist-Luenberger index for firms subject to rate-of-return regulation, it is necessary to introduce previously directional distance functions in this particular context. We have it as one of our main aims in this paper.

The paper is organized as follows. In Section 2 some preliminary concepts are introduced. Section 3 introduces directional distance functions subject to rate-of-return regulation assuming that we know input prices. It then shows how these new measures extend the regulated version of Farrell efficiency and have a dual relationship with the regulated cost function. In Section 4 we show a decomposition of the overall inefficiency into allocative inefficiency, pure technical inefficiency, and a component measuring the effect of the regulation. Section 5 discusses the possibility of considering a specific reference direction to measure inefficiency when we do not know input prices. Section 6 concludes the paper.

\section{Preliminary Notes}

We will work in the same theoretical framework as Färe and Logan [4] since one of our aims is to extend the regulated version of Farrell efficiency to directional distance functions. Therefore, it seems natural to use the same notation and theoretical axioms.

Regarding mathematical notation, we denote a vector of inputs by $x=\left(x_{1}, \ldots, x_{N}\right) \in$ $R_{+}^{N}$, and the single output by $u \in R_{+}$. The production function $F: R_{+}^{N} \rightarrow R_{+}$is defined as usual as the maximal output obtainable from each input vector. We also assume that the production function satisfies axioms that allow us to assure the existence of a dual relationship between the cost function and the technology (see [11]).

Firms subject to rate-of-return regulation face technology and regulatory constraints, where regulators set the allowed rate of return the firm can earn. To formalize the regulatory constraint let $p=\left(p_{1}, \ldots, p_{N}\right) \in R_{++}^{N}$ denote the input price vector, let $r \in R_{++}$denote the price 
of the output, and let $\alpha \in R_{++}$denote the threshold fixed by the regulator. Without loss of generality let us suppose that the Nth input represents the firm's capital investment. Then the regulatory constraint is formulated as follows:

$$
\alpha \geq \frac{r u-p x}{p_{N} x_{N}}
$$

which is equivalent to $p x+\alpha p_{N} x_{N} \geq r u$.

Following Färe and Logan [4], we use input-oriented distance functions to measure technical inefficiency. In this sense, the more usual input-oriented distance function in the literature is the Shephard input distance function [12], defined by

$$
D(u, x)=\sup \left\{\lambda: F\left(\frac{x}{\lambda}\right) \geq u\right\}
$$

In his pioneer work Farrell [13] introduced a measurement of technical efficiency which collapses to the reciprocal of (2.2). In 1992, Färe and Logan formulated the rate-of-return regulation version of the Farrell's notion of efficiency, modifying (2.2). To this end, they define the rate-of-return regulation version of the Shephard input distance function adding to (2.2) the regulatory constraint (2.1). Next we show the following expression:

$$
\widehat{D}(u, x, p, r, \alpha)=\sup \left\{\lambda: F\left(\frac{x}{\lambda}\right) \geq u, p \frac{x}{\lambda}+\alpha p_{N} \frac{x_{N}}{\lambda} \geq r u\right\}
$$

From (2.2) and (2.3), it is also possible to define the unregulated cost function and the regulated cost function, respectively, as follows:

$$
\begin{gathered}
C(u, p)=\inf _{x}\{p x: D(u, x) \geq 1\}, \\
Q(u, p, r, \alpha)=\inf _{x}\{p x: \widehat{D}(u, x, p, r, \alpha) \geq 1\} .
\end{gathered}
$$

Färe and Logan [3] established the relationship between both cost functions as follows:

$$
C(u, p)=\min _{r} Q(u, p, r, \alpha)
$$

Finally, we want to introduce in this paper directional distance functions. Directional distance functions have recently been shown to be an interesting tool in production theory, yielding the more familiar Shephard output and input distance functions as special cases $[7,8]$. Directional distance functions measure the amount that one can translate an input vector from itself to the frontier of the technology in a preassigned reference direction vector $g$. Therefore, one of the advantages of this type of distance function is that it is measured in terms of a numeraire $g$, which allows to interpret the measure in an essay way. 
Next we show the general expression of input-oriented directional distance functions [7]. Let $g \in R_{+}^{m} \backslash\left\{0_{N}\right\}$ be a vector, then the directional input distance functions can be defined as

$$
\vec{D}(u, x ; g)=\sup \{\beta: F(x-\beta g) \geq u\}
$$

or, equivalently, in terms of an optimization program dependent on prices as

$$
\vec{D}(u, x ; g)=\inf _{p}\{p x-C(u, p): p g=1\}
$$

In the particular case that $g=x$, the directional input distance function and the Shephard input distance function have the following relationship:

$$
\vec{D}(u, x ; x)=1-\frac{1}{D(u, x)} \text {. }
$$

The directional input distance function is equal to one minus the reciprocal of the Shephard input distance function. The above result shows that the directional input distance function encompasses the Shephard input distance function (see [7]).

\section{Rate-of-Return Regulation with Known Input Prices}

In this section we develop directional distance functions for firms subject to rate-of-return regulation, assuming that input prices are known.

By analogy with (2.2) and (2.3), we define a regulated version of directional input distance functions from (2.7) as

$$
\vec{D}^{R}(u, x, p, r, \alpha ; g)=\sup \left\{\beta: F(x-\beta g) \geq u, p(x-\beta g)+p_{N}\left(x_{N}-\beta g\right) \geq r u\right\} .
$$

Equation (3.1) follows the original definition of directional input distance functions but taking into account the regulatory constraint (2.1). In this way, regulator's decision can affect the level of inefficiency of the firms subject to regulation.

Next we need to prove a lemma that we will use later and that shows the relationship between (3.1) and (2.7).

Lemma 3.1. $\vec{D}^{R}(u, x, p, r, \alpha ; g)=\min \left\{\vec{D}(u, x ; g),\left(p x+\alpha p_{N} x_{N}-r u\right) /\left(p g+\alpha p_{N} g_{N}\right)\right\}$.

Proof. First of all, thanks to Theorem 9 of McFadden [14, page 49], we have that

$$
\vec{D}^{R}(u, x, p, r, \alpha ; g)=\min \left\{\sup \{\beta: F(x-\beta g) \geq u\}, \sup \left\{\beta: p(x-\beta g)+p_{N}\left(x_{N}-\beta g\right) \geq r u\right\}\right\} .
$$

By definition, the first supremum is equal to $\vec{D}(u, x ; g)$. On the other hand, the second supremum is equal to $\left(p x+\alpha p_{N} x_{N}-r u\right) /\left(p g+\alpha p_{N} g_{N}\right)$ since $p(x-\beta g)+p_{N}\left(x_{N}-\beta g\right) \geq r u$ is equivalent to write $\beta \leq\left(p x+\alpha p_{N} x_{N}-r u\right) /\left(p g+\alpha p_{N} g_{N}\right)$. 
The distance function defined by (3.1) can be used to characterize the set of feasible input vectors under rate-of-return regulation. Next we establish such result by means of the following proposition.

Proposition 3.2. $\vec{D}^{R}(u, x, p, r, \alpha ; g) \geq 0$ if and only if $F(x) \geq u$ and $p x+\alpha p_{N} x_{N} \geq r u$.

Proof. On one hand, if $\vec{D}^{R}(u, x, p, r, \alpha ; g) \geq 0$ then, thanks to Lemma 3.1, $\vec{D}(u, x ; g) \geq 0$ and $\left(p x+\alpha p_{N} x_{N}-r u\right) /\left(p g+\alpha p_{N} g_{N}\right) \geq 0$. The first implication means that $F(x) \geq u$ (see [7, page 411]). And the second implication is equivalent to $p x+\alpha p_{N} x_{N} \geq r u$.

On the other hand, if $F(x) \geq u$ then $\vec{D}(u, x ; g) \geq 0$ (see [7, page 411]). And if $p x+$ $\alpha p_{N} x_{N} \geq r u$ then $\left(p x+\alpha p_{N} x_{N}-r u\right) /\left(p g+\alpha p_{N} g_{N}\right) \geq 0$ since $p g+\alpha p_{N} g_{N}>0$. Finally, by Lemma 3.1, we achieve the desired result.

Additionally, Lemma 3.1 has an extra interpretation. We can calculate the regulated version of the directional input distance function by means of the minimum between the unregulated directional input distance function and a particular ratio. Therefore, Lemma 3.1 suggests how we can estimate (3.1) by means of parametric and nonparametric methods. Regarding the parametric methods, we can resort to flexible quadratic function for specifying a parametric directional input distance function [15], whereas, Data Envelopment Analysis (DEA) [16] can be used to estimate directional input distance functions by means of nonparametric methods.

Before focusing our analysis on proving a dual relationship between (3.1) and the regulated cost function, we would like to show that (3.1) is actually an extension of the rate-of-return regulated version of Farrell efficiency [4]. To this end, first we prove that the relationship between the directional input distance function and the Shephard input distance function, (2.9), keeps working under regulation.

Proposition 3.3. If $g=x$ then, $\vec{D}^{R}(u, x, p, r, \alpha ; x)=1-1 / \widehat{D}(u, x, p, r, \alpha)$.

Proof. Since $g=x$, and thanks to Lemma 3.1, we have that $\vec{D}^{R}(u, x, p, r, \alpha ; x)=\min \{1-$ $\left.1 / D(u, x),\left(p x+\alpha p_{N} x_{N}-r u\right) /\left(p x+\alpha p_{N} x_{N}\right)\right\}=1-1 / \min \left\{D(u, x),\left(p x+\alpha p_{N} x_{N}\right) / r u\right\}=$ $1-1 / \widehat{D}(u, x, p, r, \alpha)$, where the last equality is consequence of Proposition 2.1 in Färe and Logan [4].

As a direct consequence of Proposition 3.3, the regulated version of directional input distance functions encompasses the regulated version of Farrell efficiency. Note also that since $[1 / \widehat{D}(u, x, p, r, \alpha)]$ measures technical efficiency, $\vec{D}^{R}(u, x, p, r, \alpha ; x)$ has necessarily to measure technical inefficiency. In fact, if $[1 / \widehat{D}(u, x, p, r, \alpha)]=1$ then, thanks to Proposition 3.3, $\vec{D}^{R}(u, x, p, r, \alpha ; x)=0$. And in general, it is preferred low values of $\vec{D}^{R}(u, x, p, r, \alpha ; g)$, where zero implies the best level of inefficiency than high values.

We now turn to duality and begin with a result that relates (3.1) with (2.5). Before proceeding, we note that an important feature of the input distance functions in general, and the directional input distance function in particular, is their relationship with the (unregulated) cost function, (2.4). Under regulation it seems more suitable to study this dual correspondence with respect to the regulated version of the cost function, (2.5). And we do that next.

Proposition 3.4. One has the following

(1) $Q(u, p, r, \alpha)=\inf _{x}\left\{p x: \vec{D}^{R}(u, x, p, r, \alpha ; g) \geq 0\right\}$; 
(2) $\vec{D}^{R}(u, x, p, r, \alpha ; g)=\min \left\{\inf _{w}\left\{\sup _{\tau}\{(w x-Q(u, w, \tau, \alpha)) / w g\}\right\},\left(p x+\alpha p_{N} x_{N}-\right.\right.$ $\left.r u) /\left(p g+\alpha p_{N} g_{N}\right)\right\}$.

Proof. (1) It is a direct consequence of Proposition 3.2.

(2) Thanks to Lemma 3.1 and (2.8), we have that

$$
\begin{aligned}
\vec{D}^{R}(u, x, p, r, \alpha ; g) & =\min \left\{\inf _{w}\{w x-C(u, w): w g=1\}, \frac{p x+\alpha p_{N} x_{N}-r u}{p g+\alpha p_{N} g_{N}}\right\} \\
& =\min \left\{\inf _{w}\left\{\frac{w x-C(u, w)}{w g}\right\}, \frac{p x+\alpha p_{N} x_{N}-r u}{p g+\alpha p_{N} g_{N}}\right\} .
\end{aligned}
$$

Finally by (2.6), $\inf _{w}\{(w x-C(u, w)) / w g\}=\inf _{w}\left\{\sup _{\tau}\{(w x-Q(u, w, \tau, \alpha)) / w g\}\right\}$.

To define the regulated directional input distance function, (3.1), we resorted to solve an optimization problem in the input/output space. Instead, Proposition 3.4(2), establishes that we are able to obtain the regulated directional input distance function from an optimization problem in the price space ( $w$ for inputs and $\tau$ for the only output), given the regulated cost function.

To finish this section, we would like to point out that any vector $g \in R_{+}^{N} \backslash\left\{0_{N}\right\}$ could be used for measuring technical inefficiency by means of (3.1). The same happens with the original directional input distance function. The reference vector $g$ is arbitrarily chosen by the researchers. They generally choose this to be the observed input vector, which is in the spirit of the original Farrell measures and Shephard distance functions. Nevertheless, there are other possibilities. For example, it is quite common in the literature to take $g=$ $(1,1, \ldots, 1)$, which is mathematically equivalent to seeking the $\ell_{\infty}$-distance to the frontier of the technology (see [17]). Despite all these possibilities, it seems that the most critical issue of directional distance functions in practice is the choice of the reference direction, since their value depends significantly on $g$ (see, for more details, [18]). In contrast, in Section 5 we will show that a specific reference vector $g$ arises as a natural choice for measuring inefficiency in the case that we do not know input prices.

\section{A Measure of Overall Inefficiency}

The choice of the cost function as an economic criterion to select between alternative firms was already proposed by Farrell [13]. In this sense, the cost function can be considered as the standard against which to confront economic performance. Obviously, under regulation we will use the regulated version of the cost function, (2.5), instead of the unregulated version, (2.4), to define an overall measure of inefficiency.

In this section we will show how to assess the overall performance of each firm in terms of technical and allocative inefficiency dimensions. To achieve this goal, we resort to the Nerlove's definition of overall inefficiency [19]. This same inefficiency measure was used in Chambers et al. [8, page 360].

$$
\mathrm{NE}=\frac{(\pi(p, w)-(p y-w x))}{\left(p g_{y}+w g_{x}\right)}
$$

where $\pi(p, w)$ is the profit function and the reference vector is defined as $\left(g_{x}, g_{y}\right)$. 
Following Chambers et al. [8, page 361], technical inefficiency is measured by the unregulated directional distance function and allocative inefficiency is defined as the gap between NE and the technical inefficiency component. In this way, NE is decomposed into the sum of a technical inefficiency component and an allocative inefficiency component.

Equation (4.1) was adopted in a context in which the aim is to contract inputs and simultaneously expand outputs. In our case, we focus on contracting exclusively inputs. Therefore, we next define an input-oriented (Nerlovian) overall inefficiency measure assuming rate-of-return regulation:

$$
\mathrm{OI}(g)=\left[\frac{(p x-Q(u, p, r, \alpha))}{p g}\right]
$$

This overall inefficiency is the difference between the actual cost and the optimal cost under regulation. Since this measure is not invariant to proportional price changes, it is normalized by means of the value of the reference vector $g$, following (4.1).

Regarding the decomposition of the overall inefficiency measure, it is obvious that the technical inefficiency must correspond, following to Chambers et al. [8], to $\vec{D}^{R}(u, x, p, r, \alpha ; g)$. Then, we can obtain the allocative inefficiency component as a residual. Next we show such decomposition:

$$
\mathrm{OI}(g)=\mathrm{TI}(g)+\mathrm{AI}(g)
$$

where

$$
\begin{gathered}
\operatorname{TI}(g)=\vec{D}^{R}(u, x, p, r, \alpha ; g), \\
\mathrm{AI}(g)=\left[\frac{(p x-Q(u, p, r, \alpha))}{p g}\right]-\vec{D}^{R}(u, x, p, r, \alpha ; g) .
\end{gathered}
$$

Additionally, technical inefficiency can be decomposed into pure technical inefficiency and a component measuring the regulation effect.

$$
\mathrm{TI}(g)=\operatorname{PI}(g)+\operatorname{RE}(g),
$$

where

$$
\begin{gathered}
\operatorname{PI}(g)=\vec{D}(u, x ; g), \\
\operatorname{RE}(g)=\left[\vec{D}^{R}(u, x, p, r, \alpha ; g)-\vec{D}(u, x ; g)\right] .
\end{gathered}
$$

Pure technical inefficiency corresponds to the unregulated directional input distance function, while the regulation effect component is the difference between technical inefficiency and pure technical inefficiency. Note that pure technical inefficiency is not affected by the rate-of-return regulation constraint. Exclusively technical factors can affect this component. 


\section{Rate-of-Return Regulation with Unknown Input Prices}

First of all, we note that in the electric utility industry, and in general in most regulated natural monopolies, it is really easy to find out the quantity of generated electricity, the price of electricity, the capital investment, and even other inputs via official reports (see [20]). However, it is more difficult to obtain the actual costs of each of these inputs since they are private information of each firm. For this reason, in this section we develop directional distance functions for firms subject to rate-of-return regulation, assuming that input prices are unknown.

In order to measure technical inefficiency with directional input distance functions, we will select a specific reference direction vector $g$ which arises from the regulatory constraint in a natural way, as we show next.

We propose to work with $\tilde{x}_{i}=\left[x_{i} / r u\right], i=1, \ldots, N$, and $\tilde{u}=[u / r u]=[1 / r]$ instead of the original variables $x_{i}, i=1, \ldots, N$, and $u$. In this way, the regulatory constraint $p \tilde{x}+$ $\alpha p_{N} \tilde{x}_{N}=r \tilde{u}$, expressed in terms of the new variables, is equivalent to

$$
p_{-N} \tilde{x}_{-N}+(1+\alpha) p_{N} \tilde{x}_{N}=1,
$$

where $\tilde{x}_{-N}=\left(\tilde{x}_{1}, \ldots, \tilde{x}_{N-1}\right)$ and $p_{-N}=\left(p_{1}, \ldots, p_{N-1}\right)$.

We now turn to the expression of the directional input distance function, (2.8), as an optimization problem with the normalization constraint $p g=1$. This last linear condition, together with expression (5.1), suggests considering the reference vector $g^{R}(\alpha, \tilde{x})=$ $\left(\tilde{x}_{1}, \ldots, \tilde{x}_{N-1},(1+\alpha) \tilde{x}_{N}\right)$ to measure inefficiency under regulation. Hereafter, $g^{R}$ is shorthand for $g^{R}(\alpha, \tilde{x})$. The expression of the vector $g^{R}$ is in the spirit of the Shephard input distance function apart from the $N$-component, which appears slightly modified.

Using directional input distance functions with the specific reference vector $g^{R}$ allows us to determine a vector of shadow prices $\tilde{p}$ as a solution of $\vec{D}\left(\tilde{u}, \tilde{x} ; g^{R}\right)=\inf _{p}\{p \tilde{x}-C(\tilde{u}, p)$ : $\left.p g^{R}=1\right\}$. In particular, this vector satisfies the regulatory constraint $\alpha \geq(r \tilde{u}-\tilde{p} \tilde{x}) / \tilde{p}_{N} \tilde{x}_{N}$ thanks to (5.1). Therefore, despite we do not know the actual input prices, we are able to obtain a vector of credible prices for inputs under regulation and an associated measure of technical inefficiency $\vec{D}\left(\tilde{u}, \tilde{x} ; g^{R}\right)$.

Finally, we operationalize the approach by presenting a nonparametric DEA model and prove an interesting property of $\vec{D}\left(\tilde{u}, \tilde{x} ; g^{R}\right)$.

Let us assume that we have a set of $J$ observations (firms), $\left(x_{j}, u_{j}\right), j=1, \ldots, J$, of inputs and outputs, where $x_{j} \in R_{++}^{N}$ is observed to produce $u_{j} \in R_{++}$. Then, following Färe and Grosskopf [21], the directional input distance function $\vec{D}\left(\widetilde{u}, \widetilde{x} ; g^{R}\right)$ can be calculated in a DEA context as

$$
\begin{aligned}
\vec{D}\left(\tilde{u}, \tilde{x} ; g^{R}\right)= & \max \beta, \\
\text { s.t. } & \sum_{j=1}^{J} \lambda_{j} \tilde{u}_{j} \geq \tilde{u}, \\
& \sum_{j=1}^{J} \lambda_{j} \tilde{x}_{i j} \leq \tilde{x}_{i}-\beta \tilde{x}_{i}, \quad i=1, \ldots, N-1,
\end{aligned}
$$




$$
\begin{aligned}
& \sum_{j=1}^{J} \lambda_{j} \tilde{x}_{N j} \leq \tilde{x}_{N}-\beta(1+\alpha) \tilde{x}_{N}, \\
& \lambda_{j} \geq 0, \quad j=1, \ldots, J,
\end{aligned}
$$

where $\tilde{x}_{i j}=\left[x_{i j} / r u\right]$, for all $i=1, \ldots, N$, and for all $j=1, \ldots, J$, and $\tilde{u}_{j}=\left[u_{j} / r u\right]$, for all $j=1, \ldots, J$.

An interesting property of $\vec{D}\left(\tilde{u}, \tilde{x} ; g^{R}\right)$ is that it is not unit dependent, as we show in the following proposition.

Proposition 5.1. Let $\left\{\left(\tilde{x}_{j}, \tilde{u}_{j}\right)\right\}_{j=1, \ldots, J}$ be the set of transformed original data. Let $\vec{D}(\mu \tilde{u}, \mu \tilde{x}$; $\left.g^{R}(\alpha, \mu \tilde{x})\right)$ be the optimal value of (5.2) when one assesses $(\mu \tilde{x}, \mu \tilde{u})$ using $\left\{\left(\mu \tilde{x}_{j}, \mu \tilde{u}_{j}\right)\right\}_{j=1, \ldots, j}$. Then, $\vec{D}\left(\tilde{u}, \tilde{x} ; g^{R}(\alpha, \tilde{x})\right)=\vec{D}\left(\mu \tilde{u}, \mu \tilde{x} ; g^{R}(\alpha, \mu \tilde{x})\right)$, for all $\mu>0$.

Proof. By hypothesis,

$$
\begin{aligned}
& \vec{D}\left(\mu \tilde{u}, \mu \tilde{x} ; g^{R}(\alpha, \mu \tilde{x})\right)=\max \beta, \\
& \text { s.t. } \quad \sum_{j=1}^{J} \lambda_{j} \mu \tilde{u}_{j} \geq \mu \tilde{u}, \\
& \sum_{j=1}^{J} \lambda_{j} \mu \tilde{x}_{i j} \leq \mu \tilde{x}_{i}-\beta \mu \tilde{x}_{i}, \quad i=1, \ldots, N-1, \\
& \sum_{j=1}^{J} \lambda_{j} \mu \tilde{x}_{N j} \leq \mu \tilde{x}_{N}-\beta(1+\alpha) \mu \tilde{x}_{N}, \\
& \lambda_{j} \geq 0, \quad j=1, \ldots, J .
\end{aligned}
$$

Now, since we can drop $\mu$ of each constraint in (5.3), we directly obtain that $\vec{D}(\tilde{u}, \tilde{x}$; $\left.g^{R}(\alpha, \tilde{x})\right)=\vec{D}\left(\mu \tilde{u}, \mu \tilde{x} ; g^{R}(\alpha, \mu \tilde{x})\right)$.

As a consequence of Proposition 5.1, if we take $\mu=r u$ then the transformation that was applied on the data disappears. And therefore, the inefficiency associated to the vector $(\tilde{x}, \tilde{u})$ coincides to the inefficiency associated to the original observed vector $(x, u)$.

\section{Conclusions}

In this paper we proposed to introduce directional distance functions in the context of regulation. First, we defined this concept and showed several properties under the assumption that we knew input prices. We showed that the regulated directional input distance function collapses to the regulated Farrell efficiency measure when we consider a specific reference vector. Additionally, we defined an overall inefficiency measure to assess the performance of the firms subject to rate-of-return regulation, which can be decomposed in three terms. One 
related to the pure technical inefficiency, another one related to the regulation effect on the inefficiency, and a third component related to the allocative inefficiency of the firm.

Finally, we studied the case in which the researcher has no information about input prices. We showed that even in this case it is possible to measure inefficiency under regulation by means of directional distance function. To this aim, we resorted to the dual of the directional distance function, estimating a vector of input prices that satisfies the regulatory constraint. Such approach allowed us to suggest a specific reference direction vector for measuring technical inefficiency under regulation.

\section{Acknowledgments}

The authors are grateful to the Ministerio de Ciencia e Innovacion, Spain and to the Conselleria de Educacion, Generalitat Valenciana, for supporting this research with Grants nos. MTM2009-10479 and ACOMP/2012/144, respectively.

\section{References}

[1] H. Averch and L. L. Hohnson, "Behavior of the firm under regulatory constraint," American Economic Review, vol. 52, pp. 1052-1069, 1962.

[2] W. J. Baumol and A. K. Klevorick, "Input choices and rate-of-return regulation: an overview of the discussion," The Rand Journal of Economics, vol. 1, pp. 162-190, 1970.

[3] R. Färe and J. Logan, "The rate of return regulated firm: cost and production duality," The Bell Journal of Economics, vol. 14, no. 2, pp. 405-414, 1983.

[4] R. Färe and J. Logan, "The rate of return regulated version of farrell efficiency," International Journal of Production Economics, vol. 27, pp. 161-165, 1992.

[5] M. C. A. S. Portela, P. C. Borges, and E. Thanassoulis, "Finding closest targets in non-oriented DEA models: the case of convex and non-convex technologies," Journal of Productivity Analysis, vol. 19, pp. 251-269, 2003.

[6] R. G. Chambers and T. Mitchell, "Homotheticity and non-radial changes," Journal of Productivity Analysis, vol. 15, no. 1, pp. 31-39, 2001.

[7] R. G. Chambers, Y. Chung, and R. Färe, "Benefit and distance functions," Journal of Economic Theory, vol. 70, pp. 407-419, 1996.

[8] R. G. Chambers, Y. Chung, and R. Färe, "Profit, directional distance functions, and Nerlovian efficiency," Journal of Optimization Theory and Applications, vol. 98, no. 2, pp. 351-364, 1998.

[9] G. Granderson, "Externalities, efficiency, regulation, and productivity growth in the U.S. Electric utility industry," Journal of Productivity Analysis, vol. 26, pp. 269-287, 2006.

[10] Y. H. Chung, R. Färe, and S. Grosskopf, "Productivity and undesirable outputs: a directional distance function approach," Journal of Environmental Management, vol. 51, pp. 229-240, 1997.

[11] R. Färe and D. Primont, Multi-Output Production and Duality: Theory and Applications, Kluwer Academic, 1995.

[12] R. W. Shephard, Cost and Production Functions, Princeton University Press, Princeton, NJ, USA, 1953.

[13] M. Farrell, "The masurement of productive efficiency," Journal of the Royal Statistical Society A, vol. 120, pp. 253-281, 1957.

[14] D. McFadden, "Cost, revenue and profit functions," in Production Economics: A Dual Approach to Theory and Application, M. Fuss and D. McFadden, Eds., vol. 1, pp. 1-110, North Holland, Amsterdam, The Netherlands, 1978.

[15] R. Färe, S. Grosskopf, D.-W. Noh, and W. Weber, "Characteristics of a polluting technology: theory and practice," Journal of Econometrics, vol. 126, no. 2, pp. 469-492, 2005.

[16] A. Charnes, W. W. Cooper, and E. Rhodes, "Measuring the efficiency of decision making units," European Journal of Operational Research, vol. 2, no. 6, pp. 429-444, 1978.

[17] W. Briec and J. B. Lesourd, "Metric distance function and profit: some duality results," Journal of Optimization Theory and Applications, vol. 101, no. 1, pp. 15-33, 1999. 
[18] R. G. Chambers and R. Färe, Technical Efficiency Measurement: The Choice of Direction. V North American Productivity Workshop, Stern School of Business, New York University, New York, NY, USA, 2008.

[19] M. Nerlove, Estimation and Identification of Cobb-Douglas Production Functions, Rand McNally Company, Chicago, Ill, USA, 1965.

[20] R. Weron, Modeling and Forecasting Electricity Loads and Prices, John Wiley \& Sons, Chichester, UK, 2006.

[21] R. Färe and S. Grosskopf, "Theory and applications of directional distance functions," Journal of Productivity Analysis, vol. 13, pp. 93-103, 2000. 


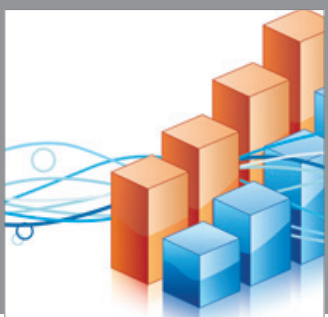

Advances in

Operations Research

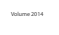

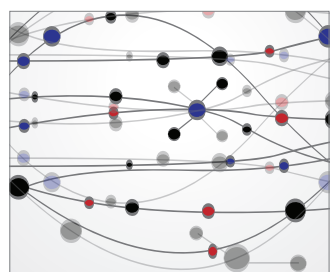

\section{The Scientific} World Journal
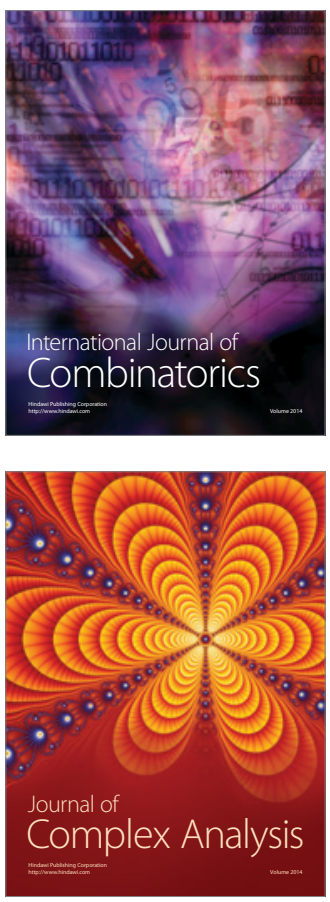

International Journal of

Mathematics and

Mathematical

Sciences
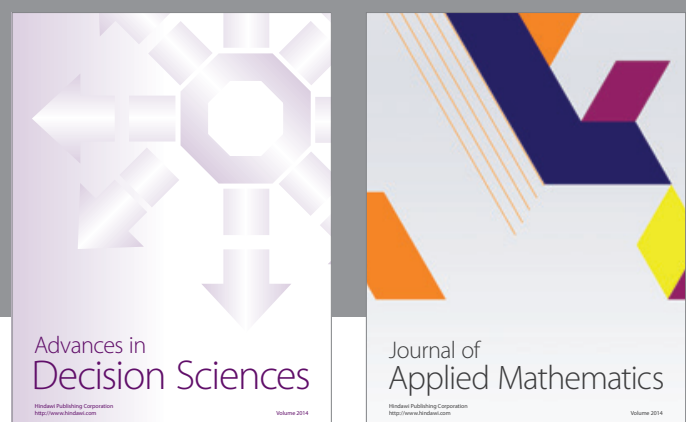

Journal of

Applied Mathematics
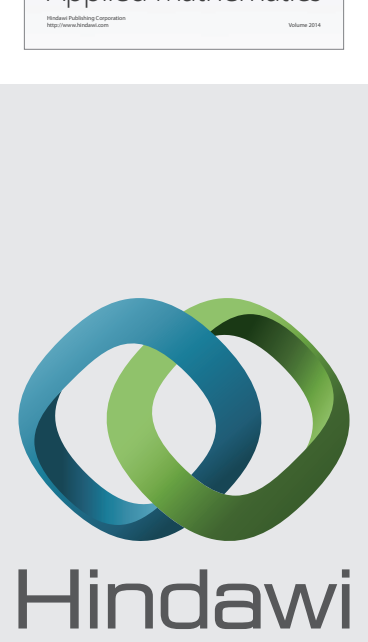

Submit your manuscripts at http://www.hindawi.com
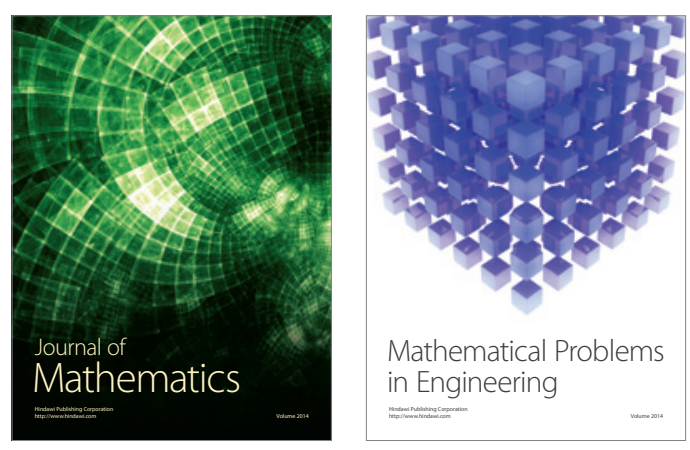

Mathematical Problems in Engineering
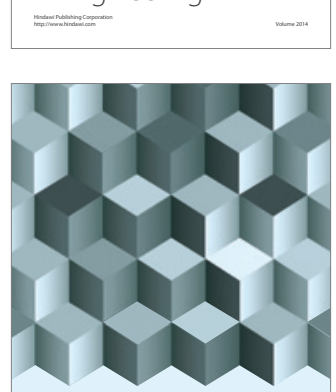

Journal of

Function Spaces
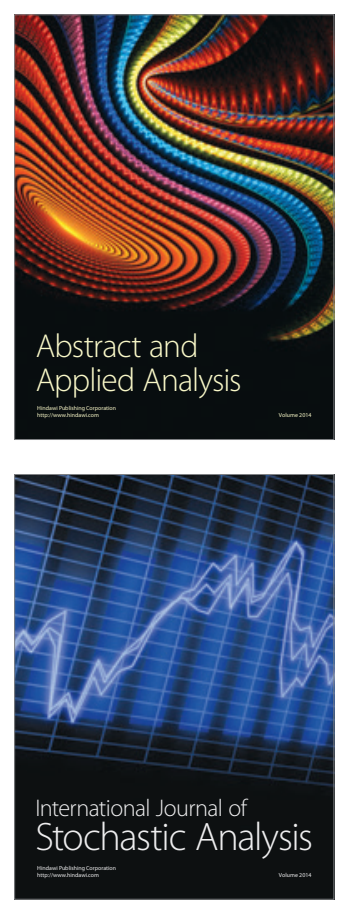

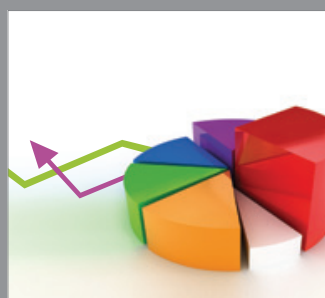

ournal of

Probability and Statistics

Promensencen
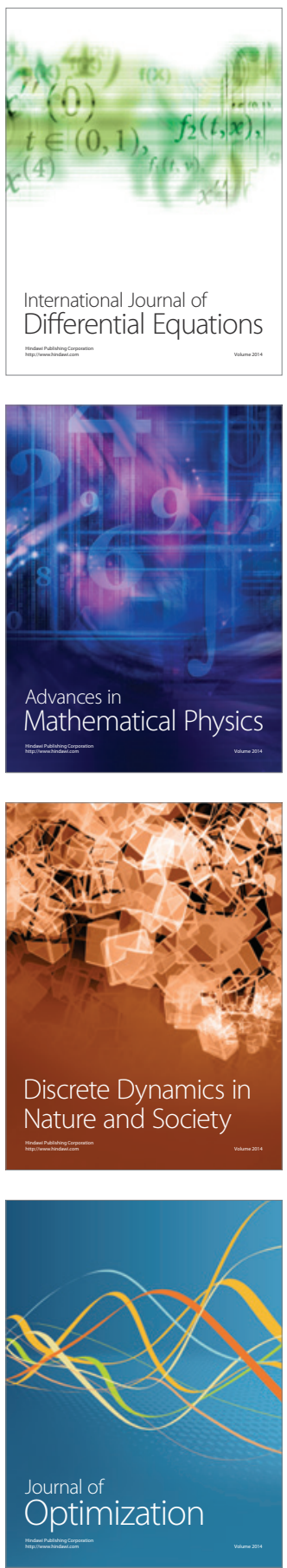